\title{
Monitoring the integrity and usability of policy evaluation tools within an evolving socio-cultural context: A demonstration of reflexivity using the CFPC Family Medicine Longitudinal Survey
}

\author{
Deena Hamza ${ }^{1}$ and Lawrence Grierson ${ }^{2}$ \\ ${ }^{1}$ University of Alberta \\ ${ }^{2}$ Affiliation not available
}

October 4, 2021

\begin{abstract}
Rationale, aims and objectives: Over the last decade, policy changes have prompted Canadian medical education to emphasize a transformation to competency-based education, and subsequent development of evaluation tools. The pandemic provides a unique opportunity to emphasize the value of reflexive monitoring, a cyclical and iterative process of appraisal and adaptation, since tools are influenced by social and cultural factors relevant at the time of their development. Methods: Deductive content analysis of documents and resources about the advancement of primary care. Reflexive monitoring of the Family Medicine Longitudinal Survey (FMLS), an evaluation tool for physician training. Results: The FMLS tool does not explore all training experiences that are currently relevant; including, incorporating technology, infection control and safety, public health services referrals, patient preferences for care modality, and trauma-informed culturally safe care. Conclusion: The results illustrate that reflection promotes the validity and usefulness of the data collected to inform policy performance and other initiatives. Keywords: program evaluation; health professions education; reflexive monitoring; competency-based education; healthcare policy
\end{abstract}

\section{Hosted file}

ReflexiveMonitoring - JECP.docx available at https://authorea.com/users/439418/articles/ 540364-monitoring-the-integrity-and-usability-of-policy-evaluation-tools-within-anevolving-socio-cultural-context-a-demonstration-of-reflexivity-using-the-cfpc-familymedicine-longitudinal-survey

\section{Hosted file}

Figure_1.docx available at https://authorea.com/users/439418/articles/540364-monitoring-theintegrity-and-usability-of-policy-evaluation-tools-within-an-evolving-socio-culturalcontext-a-demonstration-of-reflexivity-using-the-cfpc-family-medicine-longitudinalsurvey 